Check for updates

Cite this: RSC Adv., 2020, 10, 20145

\title{
Peat-derived hard carbon electrodes with superior capacity for sodium-ion batteries $\uparrow$
}

\author{
Anu Adamson, ${ }^{a}$ Ronald Väli, ${ }^{a}$ Maarja Paalo, ${ }^{a}$ Jaan Aruväli, ${ }^{\text {b }}$ Miriam Koppel, ${ }^{a}$ \\ Rasmus Palm, ${ }^{a}$ Eneli Härk, ${ }^{c}$ Jaak Nerut, ${ }^{a}$ Tavo Romann, ${ }^{a}$ Enn Lust ${ }^{a}$ and Alar Jänes (iD *a \\ Herein we demonstrate how peat, abundant and cheap biomass, can be successfully used as a precursor to \\ synthesize peat-derived hard carbons (PDCs), applicable as electrode materials for sodium-ion batteries \\ (SIB). The PDCs were obtained by pre-pyrolysing peat at $300-800{ }^{\circ} \mathrm{C}$, removing impurities with base- \\ acid solution treatment and thereafter post-pyrolysing the materials at temperatures $(T$ ) from 1000 to \\ $1500{ }^{\circ} \mathrm{C}$. By modification of pre- and post-pyrolysis temperatures we obtained hard carbons with low \\ surface areas, optimal carbonization degree and high electrochemical $\mathrm{Na}^{+}$storage capacity in SIB half- \\ cells. The best results were obtained when pre-pyrolysing peat at $450{ }^{\circ} \mathrm{C}$, washing out the impurities \\ with $\mathrm{KOH}$ and $\mathrm{HCl}$ solutions and then post-pyrolysing the obtained carbon-rich material at $1400{ }^{\circ} \mathrm{C}$. All \\ hard carbons were electrochemically characterized in half-cells $\left(v s . \mathrm{Na} / \mathrm{Na}^{+}\right)$and capacities as high as \\ $350 \mathrm{~mA} \mathrm{~h} \mathrm{~g}^{-1}$ at $1.5 \mathrm{~V}$ and $250 \mathrm{~mA} \mathrm{~h} \mathrm{~g}^{-1}$ in the plateau region $(E<0.2 \mathrm{~V}$ ) were achieved at charging \\ current density of $25 \mathrm{~mA} \mathrm{~g}^{-1}$ with an initial coulombic efficiency of $80 \%$.
}

Received 9th April 2020

Accepted 20th May 2020

DOI: $10.1039 / \mathrm{dO}$ ra03212c

rsc.li/rsc-advances
(372 $\left.\mathrm{mA} \mathrm{h}^{-1}\right),{ }^{11,12}$ is not applicable in SIBs since the theoretical capacity of graphite in SIB is only $35 \mathrm{~mA} \mathrm{~h} \mathrm{~g}^{-1.13}$ Since $\mathrm{Na}^{+}$is bigger than $\mathrm{Li}^{+}$, the intercalation of $\mathrm{Na}^{+}$into graphite stretches the $\mathrm{C}-\mathrm{C}$ bonds in graphite-like structures more than $\mathrm{Li}$. Consequently, it has been shown, that the Na-graphite intercalation compound (Na-GIC) is highly unstable. ${ }^{14}$

Different types of materials have been explored as the negative electrodes for SIB, including metal oxides/alloys, but carbon materials (hard carbons in particular with specific properties) have emerged as the most promising of all the proposed materials. ${ }^{15}$ Hard carbons have demonstrated high capacities and structural properties that make them potentially applicable for the use as negative electrodes in SIBs. ${ }^{16}$

Hard carbons have attracted attention due to their high plateau capacity at low potential $\left(E<0.2 \mathrm{~V} \mathrm{Na} / \mathrm{Na}^{+}\right)$which enables high specific energy. ${ }^{17}$ There are many specific structural properties of hard carbon that influence the electrochemical performance of SIBs. It has been shown that some carbons with low specific surface area and a specific degree of graphitization are preferable for use in SIBs. ${ }^{\mathbf{1 8 , 1 9}}$ Thus, choosing the hard carbon with optimal properties has a great impact on the performance of the SIB, especially on the irreversible capacity (IRC) of the $1^{\text {st }}$ cycle and initial charging/discharging coulombic efficiency (ICE). This is related to the formation of the solid electrolyte interface (SEI) layer on the surface of a carbon electrode. SEI forms during the $1^{\text {st }}$ charging cycle when sodium ions intercalate into the hard carbon and the nonaqueous electrolyte partly decomposes. ${ }^{20}$ Many of the intercalated sodium ions react with the decomposition products of the electrolyte and are therefore irreversibly lost to the formation of 
SEI layer. ${ }^{18,21}$ Therefore, the lower surface area of carbon is preferable since it also means less surface area for the formation of SEI.

Hard carbons can be synthesized from many different precursor materials, such as polymers, sugars ${ }^{22,23}$ or biomass. ${ }^{16}$ Some biomass-derived hard carbons have been shown to be highly effective as SIB negative electrode materials. For example, the capacities of 181, 280, 350 and $360 \mathrm{~mA} \mathrm{~h} \mathrm{~g}$ were achieved for pomelo peels, ${ }^{24}$ coconut oil, ${ }^{25}$ lotus stem ${ }^{26}$ and carbonized leaves ${ }^{27}$ based SIBs, respectively.

In this study, highly decomposed Estonian peat was used as a precursor for the synthesis of hard carbon. The natural cellular structure of peat may be useful in order to obtain the hard carbon structure necessary to promote sodium ion (de) intercalation. The peat moss derived carbon previously used in SIB application has demonstrated capacities up to $275 \mathrm{~mA} \mathrm{~h} \mathrm{~g}^{-1}$, with a plateau of $180 \mathrm{~mA} \mathrm{~h} \mathrm{~g}^{-1}$ below $0.2 \mathrm{Vvs.} \mathrm{Na} /$ $\mathrm{Na}^{+}{ }^{28}$ One of the main advantages of peat is that it can be excavated from bogs and collected effectively in millions of tons, in comparison with the tediousness of collecting, say, banana peels from recycled waste.

Sometimes a serious drawback of biomass precursors is their impurity content. Some research on the removal of impurities from the biomass precursors has been conducted, ${ }^{29-31}$ but universal solutions are not yet available. The most pronounced problem with the inorganic impurities is their inactiveness in electrochemical processes by lowering the specific energy of the material by acting as deadweight. Although a great extent of research has been made to establish the effect of the pyrolysis temperature on the performance of biomass-derived hard carbons in SIBs, ${ }^{29,30,32,33}$ fewer studies have been conducted to analyze the effect of pyrolysis temperature in a multi-step carbon synthesis process on $\mathrm{Na}^{+}$storage characteristics. In this study, a multi-step synthesis process has been developed, where the peat biomass precursor is pre-pyrolysed at a lower temperature $\left(<1000{ }^{\circ} \mathrm{C}\right)$, thereafter washed with $\mathrm{KOH}$ and $\mathrm{HCl}$ aqueous solutions and finally post-pyrolysed at a higher temperature $\left(>1000{ }^{\circ} \mathrm{C}\right)$. Both the pre- and post-pyrolysis temperatures have been varied systematically and, also, the effect on structural properties of the cleaning ( $\mathrm{KOH}$ and $\mathrm{HCl}$ treatment) of the carbon material in between the pyrolysis stages has also been studied. The goal was to examine the effect of the adjustment and optimization of these synthesis steps on obtained peat derived hard carbons' properties. Furthermore, influence of pre- and post-treatment steps of obtained hard carbons on the energy storage capability of SIBs has been demonstrated.

\section{Experimental}

\section{Synthesis of hard carbon materials}

Highly decomposed peat was obtained from Möllatsi bog in Tartumaa, Estonia. The peat-derived carbon (PDC) was prepared in three steps. Firstly, the peat was washed with water $\left(\mathrm{MilliQ}^{+}\right)$, then homogenized and pre-pyrolysed for $3 \mathrm{~h}$ at fixed temperatures from 300 to $800{ }^{\circ} \mathrm{C}$ (at $100{ }^{\circ} \mathrm{C}$ interval). Obtained carbonaceous material was thereafter stirred for $2 \mathrm{~h}$ in $20 \%$
$\mathrm{KOH}$ aqueous solution at $70{ }^{\circ} \mathrm{C}$. Thereafter, $50 \mathrm{vol} \% \mathrm{HCl}$ solution was added until the $\mathrm{pH}$ of the solution reached $\sim 1$, and the solution was stirred overnight. The treatment with $\mathrm{HCl}$ probably contributed to the increased content of chloride anions in the carbonaceous materials (Table S1 in ESI $\dagger$ ). In order to thoroughly clean and eliminate the residual chlorine anions, the carbonaceous materials were stirred overnight in $\mathrm{MilliQ}^{+}$water and dried in a vacuum oven. As a final crucial step, the carbonaceous materials were post-pyrolysed at fixed temperatures from 1000 to $1500{ }^{\circ} \mathrm{C}$ with a $100{ }^{\circ} \mathrm{C}$ interval. The pre-pyrolysis was carried out in a quartz-tube furnace (Carbolite) and postpyrolysis in an $\mathrm{Al}_{2} \mathrm{O}_{3}$-tube furnace (Carbolite Gero). The nomenclature and synthesis of obtained hard carbons are shown in Fig. 1.

\section{Characterization of hard carbon materials}

The structure of the synthesized hard carbons was investigated with X-ray diffraction (XRD), Raman spectroscopy, gas sorption (with $\mathrm{N}_{2}$ and $\mathrm{Ar}$ ), scanning electron microscopy coupled with energy dispersive X-ray spectrometry (SEM-EDX), transmission electron microscopy (TEM) and laser powder diffraction (LPD) methods. The thermogravimetric analysis (TGA) was performed to evaluate the burn-off of peat's organic content during prepyrolysis. In order to evaluate the effect of the $\mathrm{KOH}-\mathrm{HCl}$ treatment on hard carbon, the elemental composition was investigated before and after the treatment using X-ray fluorescence spectrometry (XRF).

The XRF measurements were performed using Rigaku wavedispersive X-ray fluorescence spectrometer SZX Primus II. Rh primary radiation with a power of $3 \mathrm{~kW}$ was used. All elements from $\mathrm{C}$ to $\mathrm{U}$ were measured from $20 \mathrm{~mm}$ pellets into which the powder samples were pressed. The pellets were covered with a 6 $\mu \mathrm{m}$ thick polyester plastic (Mylar, DuPont), the signal of which was subtracted. The results were calculated with the ScanQuantX method. XRD measurements were executed with Bruker $\mathrm{X}$-ray diffractometer $\mathrm{D} 8$ Advance. Ni-filtered $\mathrm{Cu} \mathrm{K} \alpha$ radiation was used. Raman spectra were acquired with Renishaw inVia Raman microscope and Ar laser with a wavelength of $514 \mathrm{~nm}$ was used for excitation.

TEM micrographs have been selected from TEM measurement data conducted using JEOL JEM-2100 (JEOL GmbH, Eching, Germany) instrument with an acceleration voltage of 200 $\mathrm{kV}$.

For each powder sample, multiple spectra were measured from different areas on the sample and the averaged information of 3-6 spectra was used for further analysis. The first-order Raman spectra were deconvoluted using the Gaussian and Lorentz distribution functions. Gas sorption measurements were carried out with TriFlex and ASAP 2020 systems. The samples were degassed for more than $3 \mathrm{~h}$ at 0.05 mbar. Nitrogen (Linde Gas, 6.0) and argon (Linde Gas, 6.0) sorption measurements were conducted at $77 \mathrm{~K}$ and $87 \mathrm{~K}$, correspondingly.

The specific surface area of the hard carbon materials was calculated according to BET $\left(\mathrm{N}_{2}\right)$ and NLDFT (Ar) theories. For some materials, pore size distributions were also calculated, 


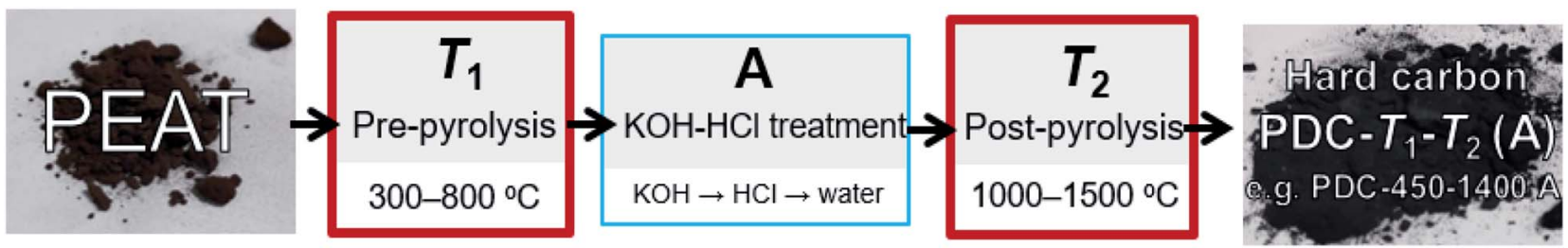

Fig. 1 Synthesis steps and nomenclature of obtained hard carbons: $T_{1}$ marks the pre-pyrolysis temperature (synthesis of peat to carbonaceous material). The letter A appended to the ending of hard carbon notation indicates that between two pyrolysis stages, the material was treated with $\mathrm{KOH}$ and $\mathrm{HCl} . \mathrm{T}_{2}$ marks the post-pyrolysis temperature (synthesis of carbonaceous material to carbon).
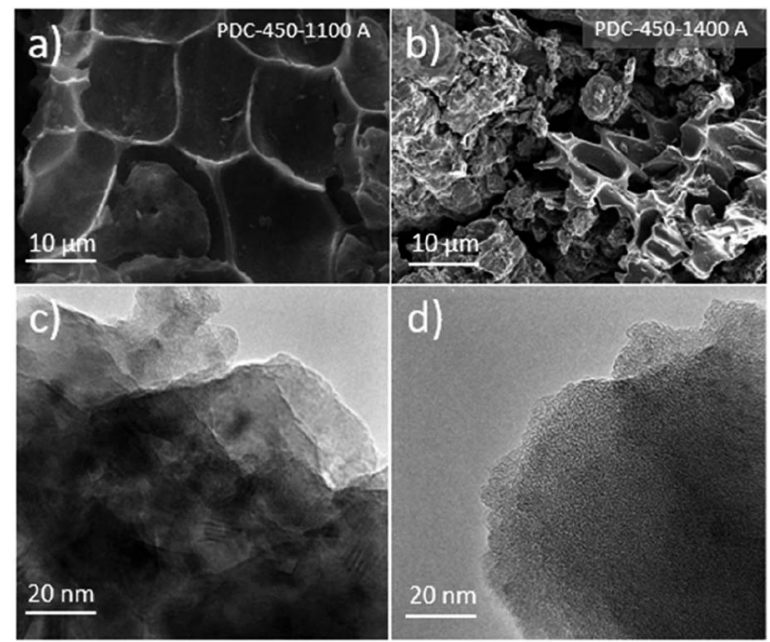

Fig. 2 SEM images for PDC-450-1100 A (a) and PDC-450-1400 A (b). TEM images for PDC-500 (c) and (d) taken from different sites of the material.

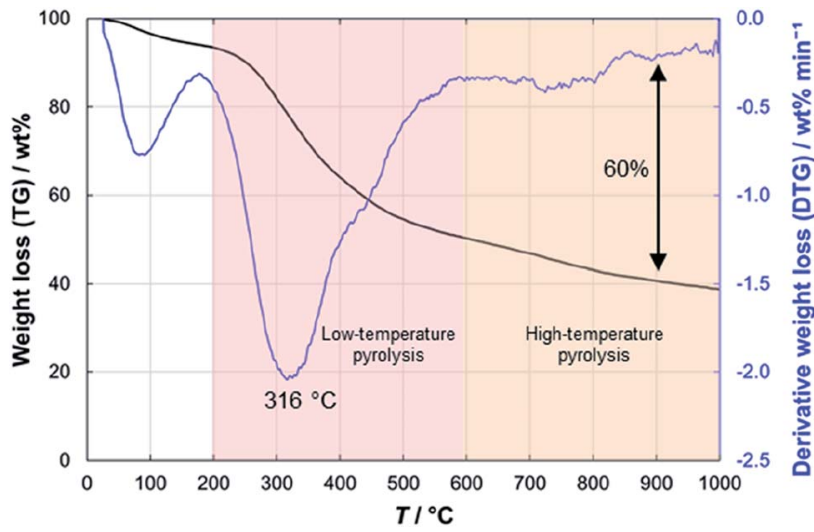

Fig. 3 Thermogravimetric analysis results for peat.

using the SAIEUS carbon N2-77 2D-NLDFT heterogeneous surface model. ${ }^{34}$

Thermogravimetric analysis (TGA) of peat was performed with NETZSCH STA449F3 using an $\mathrm{Al}_{2} \mathrm{O}_{3}$ crucible. During the measurement, the temperature increased from 25 to $1000{ }^{\circ} \mathrm{C}$ with a heating up rate of $10^{\circ} \mathrm{C} \mathrm{min}{ }^{-1}$. The flow rate of nitrogen (Linde Gas, 3.0) was $50 \mathrm{~cm}^{3} \mathrm{~min}^{-1}$. Laser powder diffraction (LPD) was used to measure the relative particle sizes of obtained pre-pyrolysed carbonaceous materials (PDC- $\left.T_{1}\right)$. It was conducted with a Microtrac S3500 Bluewave instrument using ultrasound to separate agglomerates that may have formed.

\section{Electrochemical characterization of hard carbon materials}

The obtained hard carbon was ground and mixed with conductive carbon black Super P (Alfa Aesar) and polyvinylidene difluoride (PVDF) in a $75: 15: 10$ weight ratio in $N$-methyl-2pyrrolidone (NMP, Sigma-Aldrich, 99.5\%) mixture to form electrode slurry. The resulting mixture was cast onto aluminium foil using a doctor blade and thereafter dried on a hotplate. Electrode discs with a geometric area of $2 \mathrm{~cm}^{2}$ were cut and dried under vacuum at $120{ }^{\circ} \mathrm{C}$ for $16 \mathrm{~h}$. The mass-loading of active material in most cases was around $1.75 \mathrm{mg} \mathrm{cm}^{-2}$.

Electrochemical characterization was carried out in the halfcells using sodium metal (Acros, 99.8\%) as a counter electrode and $1.55 \mathrm{~mm}$ glass fibre as a separator EL-Cell $\mathrm{GmbH}$ in the 2032-type coin cells. Measurements were carried out comparing two electrolytes: $1 \mathrm{M} \mathrm{NaClO}_{4}$ (Alfa Aesar, $99 \%$ ) solution in $1: 1$ (v/v) ethylene carbonate (EC, Sigma-Aldrich, 99\%) and diethyl carbonate (DEC, Sigma-Aldrich, 99\%) mixture and $1 \mathrm{M} \mathrm{NaPF}_{6}$ solution in $1: 1(\mathrm{v} / \mathrm{v})$ EC and propylene carbonate (PC, SigmaAldrich, 99.7\%). All cells were assembled in an Ar-filled glove box $\left(\mathrm{O}_{2}\right.$ and $\left.\mathrm{H}_{2} \mathrm{O}<0.1 \mathrm{ppm}\right)$.

Cycling performance of the PDC electrodes has been investigated using galvanostatic charge/discharge method at current densities ranging from 25 to $2000 \mathrm{~mA} \mathrm{~g}^{-1}$. The current density and capacity values have been expressed per active material of the working electrode, and the cycling has been carried out from 0.005 to $1.5 \mathrm{~V}\left(v s\right.$. $\left.\mathrm{Na} / \mathrm{Na}^{+}\right)$.

\section{Results and discussion}

\section{SEM-EDX and TEM measurements}

SEM images demonstrate that peat's natural cellular structure is still preserved (Fig. $2 \mathrm{a}$ and b), even after the fairly destructive synthesis steps. SEM-EDX of selected carbon samples demonstrates that the increase in the post-pyrolysis temperature gives rise to hard carbons with higher carbon content and lower impurity content (Table S1 $\dagger$ ). However, the change in carbon content does not appear to have much influence on the morphology or topography of the carbon samples prepared (Fig. S1†).

TEM images taken of PDC-500 (Fig. 2c and d) indicate a mix of amorphous carbon and some $\left(\mathrm{Ca}(\mathrm{OH})_{2}\right.$ and $\left.\mathrm{Fe}(\mathrm{OH})_{2}\right)$ crystals 

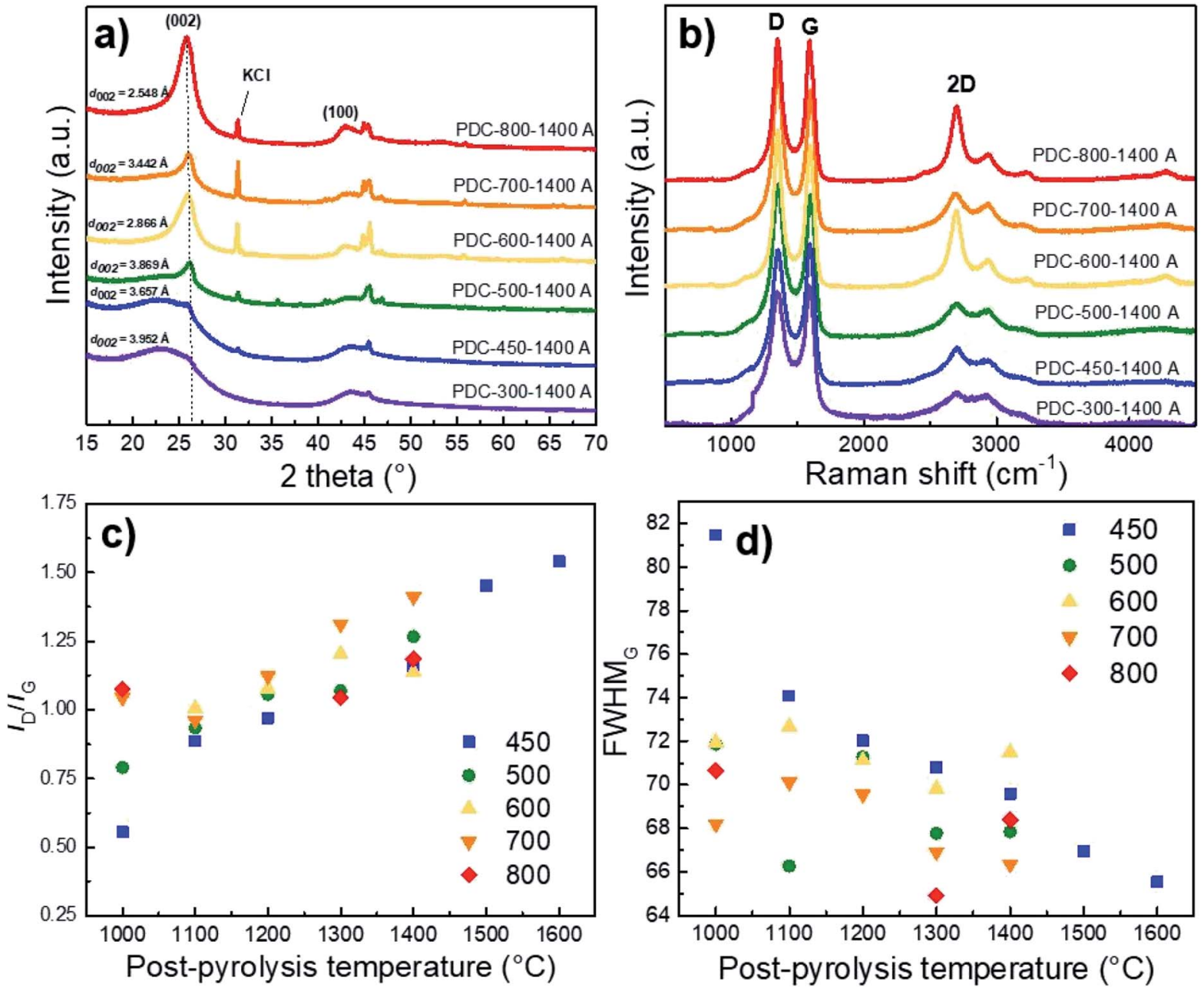

Fig. 4 The effect of pre-pyrolysis temperature on the XRD diffractograms (a), Raman spectra (b), $I_{D} / I_{G}$ ratio (c), and FWHM $M_{G}$ calculated from Raman spectra of hard carbons with various post-pyrolysis temperatures $\left(T_{2}, x\right.$-axis) and with pre-pyrolysis temperatures ( $\left.T_{1}\right)$ ranging from 400 to $800{ }^{\circ} \mathrm{C}$ (noted in figure) (d).

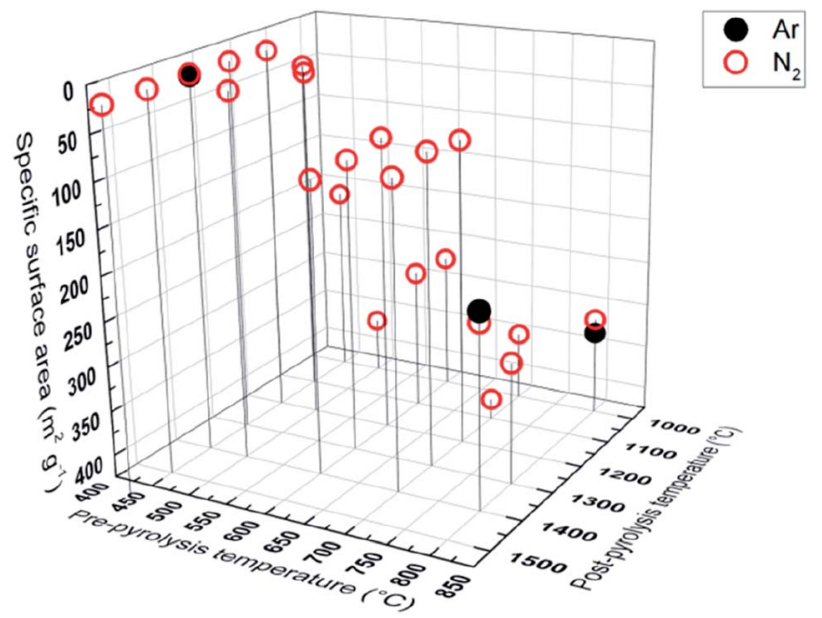

Fig. 5 Gas sorption measurements with $\mathrm{Ar}$ and $\mathrm{N}_{2}$, showing correlation between pyrolysis temperature and specific surface. embedded within the carbon structure, as demonstrated by XRD and XRF measurements. However, because of the too amorphous structure and existence of some impurities, it was not possible to determine the layer spacing from the TEM images.

\section{Thermogravimetric analysis and laser powder diffraction}

In the thermogravimetric analysis of the precursor peat, several characteristic stages during the heating process can be distinguished (Fig. 3). Firstly, around $100{ }^{\circ} \mathrm{C}$ water evaporates from the sample and causes a 5-6 wt\% decrease in the sample weight. At $200{ }^{\circ} \mathrm{C}$, the low-temperature pyrolysis stage begins, which accounts for $45 \mathrm{wt} \%$ decrease in the mass of the sample. In the final, high-temperature stage of pyrolysis at $>600{ }^{\circ} \mathrm{C}$, the slower weight loss takes place. Finally, at $1000{ }^{\circ} \mathrm{C}$ about $40 \mathrm{wt} \%$ of the initial mass of peat remains. Nearly similar patterns have been observed for peats of different origin. ${ }^{35-37}$

The particle sizes of only pre-pyrolysed PDCs were also measured, using the laser diffraction method. At $T_{1}=600{ }^{\circ} \mathrm{C}$, where the burn-off process reached a plateau, the formulated particles were significantly smaller, compared to the other only 
Table 1 Electrochemical performance metrics of studied hard carbon materials

\begin{tabular}{|c|c|c|c|c|c|c|c|}
\hline Sample & ICE & $\begin{array}{l}Q_{0.07 \mathrm{C}} / E=1.5 \mathrm{~V} \\
\left(\mathrm{~mA} \mathrm{~h} \mathrm{~g}^{-1}\right)\end{array}$ & $\begin{array}{l}Q_{0.07 \mathrm{C}} / E<0.2 \mathrm{~V} \\
\left(\mathrm{~mA} \mathrm{~h} \mathrm{~g}^{-1}\right)\end{array}$ & $\begin{array}{l}Q_{0.14 \mathrm{C}} / E=1.5 \mathrm{~V} \\
\left(\mathrm{~mA} \mathrm{~h} \mathrm{~g}^{-1}\right)\end{array}$ & $\begin{array}{l}Q_{0.14 \mathrm{C}} / E<0.2 \mathrm{~V} \\
\left(\mathrm{~mA} \mathrm{~h} \mathrm{~g}^{-1}\right)\end{array}$ & $\begin{array}{l}Q_{0.3 \mathrm{C}} / E=1.5 \mathrm{~V} \\
\left(\mathrm{~mA} \mathrm{~h} \mathrm{~g}^{-1}\right)\end{array}$ & $\begin{array}{l}Q_{0.3 \mathrm{C}} / E<0.2 \mathrm{~V} \\
\left(\mathrm{~mA} \mathrm{~h}^{-1}\right)\end{array}$ \\
\hline PDC-300-1400 A & $77 \%$ & 321 & 233 & 256 & 178 & 161 & 87 \\
\hline PDC-450-1000 A & $74 \%$ & 301 & 174 & 278 & 166 & 262 & 154 \\
\hline PDC-450-1100 A & $75 \%$ & 328 & 205 & 294 & 189 & 268 & 167 \\
\hline PDC-450-1200 A & $75 \%$ & 326 & 217 & 301 & 204 & 277 & 186 \\
\hline PDC-450-1300 A & $78 \%$ & 329 & 233 & 295 & 210 & 242 & 161 \\
\hline PDC-450-1400 A & $80 \%$ & 356 & 262 & 332 & 245 & 300 & 221 \\
\hline PDC-450-1500 A & $74 \%$ & 333 & 246 & 257 & 194 & 163 & 103 \\
\hline PDC-500-1000 A & $62 \%$ & 250 & 133 & 225 & 127 & 206 & 111 \\
\hline PDC-500-1100 A & $64 \%$ & 248 & 144 & 212 & 124 & 191 & 106 \\
\hline PDC-500-1200 A & $71 \%$ & 300 & 201 & 252 & 171 & 240 & 162 \\
\hline PDC-500-1300 A & $70 \%$ & 224 & 162 & 163 & 117 & 168 & 115 \\
\hline PDC-500-1400 A & $73 \%$ & 306 & 233 & 201 & 140 & 164 & 102 \\
\hline PDC-600-1000 A & $39 \%$ & 94 & 43 & 73 & 29 & 60 & 20 \\
\hline PDC-600-1100 A & $37 \%$ & 84 & 43 & 60 & 25 & 47 & 14 \\
\hline PDC-600-1200 A & $51 \%$ & 142 & 99 & 73 & 39 & 50 & 18 \\
\hline PDC-600-1300 A & $49 \%$ & 134 & 95 & 70 & 37 & 46 & 16 \\
\hline PDC-600-1400 A & $58 \%$ & 216 & 165 & 131 & 92 & 59 & 24 \\
\hline PDC-700-1000 A & $50 \%$ & 147 & 69 & 127 & 57 & 103 & 41 \\
\hline PDC-700-1100 A & $51 \%$ & 158 & 83 & 137 & 75 & 113 & 54 \\
\hline PDC-700-1200 A & $56 \%$ & 206 & 140 & 121 & 70 & 73 & 24 \\
\hline PDC-700-1300 A & $66 \%$ & 279 & 209 & 197 & 138 & 112 & 57 \\
\hline PDC-700-1400 A & $67 \%$ & 290 & 223 & 180 & 125 & 113 & 63 \\
\hline PDC-800-1000 A & $33 \%$ & 128 & 53 & 109 & 50 & 98 & 42 \\
\hline PDC-800-1300 A & $43 \%$ & 165 & 106 & 123 & 73 & 93 & 48 \\
\hline PDC-800-1400 A & $50 \%$ & 188 & 135 & 142 & 94 & 101 & 56 \\
\hline
\end{tabular}

pre-pyrolysed PDCs. The particle sizes of all the measured PDCs were around $6 \mu \mathrm{m}$. However, for PDC-600, the number was almost twice as small (Table $\mathrm{S} 2 \dagger$ ).

\section{X-ray fluorescence spectroscopy}

The XRF studies of the precursor peat show that the peat contains significant amounts of $\mathrm{Ca}$ and Fe (Table S2 $\dagger$ ) which would be electrochemically inactive and therefore needed to be removed. XRF data also shows that the materials pre-pyrolysed at lower temperatures contain more $\mathrm{Ca}$ and $\mathrm{Fe}\left(T_{1}=450{ }^{\circ} \mathrm{C}\right.$, $\left.w_{\mathrm{Ca} \%}=19.3\right)$ than materials pre-pyrolysed at higher temperatures $\left(T_{1}=800{ }^{\circ} \mathrm{C}, w_{\mathrm{Ca} \%}=8.2\right)$. However, after $\mathrm{KOH}$ and $\mathrm{HCl}$ treatment steps the materials pre-pyrolysed at lower temperatures contained less $\mathrm{Ca}$ (and $\mathrm{Fe})\left(T_{1}=450{ }^{\circ} \mathrm{C}, w_{\mathrm{Ca} \%}=0.38\right)$ than the materials pre-pyrolysed at higher temperatures $\left(T_{1}=800{ }^{\circ} \mathrm{C}\right.$, $\left.w_{\mathrm{Ca} \%}=2.7\right)$.

Therefore, the biggest effect of $\mathrm{KOH}$ and $\mathrm{HCl}$ treatment steps was to reduce the Ca-content of pre-pyrolysed carbons, however, the content of Fe also decreased (Table $\mathrm{S} 2 \dagger$ ). This phenomenon can be explained by the encapsulation of Fe and Ca compounds during pre-pyrolysis at higher temperatures.

\section{X-ray diffraction analysis}

XRD results show that $\mathrm{Ca}$ and Fe exist mostly in the form of oxides/hydroxides and that the $\mathrm{KOH}$ and $\mathrm{HCl}$ treatment steps cause a high $\mathrm{KCl}$ content in the materials if $T_{1}>500{ }^{\circ} \mathrm{C}$ has been applied (Fig. S2 $\dagger$ ). It must be said that higher pyrolysis temperature always contributes to increased graphitization. ${ }^{38,39}$
However, Fig. 4a demonstrates the high content of non-carbon compounds in PDC pre-pyrolysed at $600{ }^{\circ} \mathrm{C}$ and post-pyrolysed at $1400{ }^{\circ} \mathrm{C}$ (noted as PDC-600-1400 A) and a high $d_{002}$ reflex, indicating its graphitization. Whereas the impurity content in PDC-700-1400 A is lower, as is the $d_{002}$ reflex, being therefore less graphitized. The hard carbon synthesized at the highest pre-pyrolysis temperature (PDC-800-1400 A) is nevertheless the most graphitized-therefore both PDC-800-1400 A and PDC600-1400 A demonstrate that the content of non-carbon compounds and temperature definitely play a role in the graphitization step. Similar phenomenon, where Fe acts as a catalyst for graphitization in biomass precursor, has been found in literature. ${ }^{40}$ It must be noted, that at $T_{1}=600{ }^{\circ} \mathrm{C}$ (as discussed earlier), significantly smaller particles were formed and it is intuitive that graphitization would occur more readily in the case of smaller particles because of extra space for atoms to reorganize. Materials with low impurity contents $\left(T_{1}<500\right.$ ${ }^{\circ} \mathrm{C}$ ), also display small $d_{002}$ peaks, indicating the formation of local graphitic domains, a characteristic of high capacity hard carbons. ${ }^{19}$

The average layer spacing was calculated for obtained hard carbons using DIFFRAC.EVA software. As a general trend, the interlayer spacing decreases with increasing the pre-pyrolysis temperature. However, PDC-600-1400 A is an exception, which is consistent with Raman spectroscopy and gas sorption measurements. The main reason is the formation of much smaller particles during the pre-pyrolysis at $600{ }^{\circ} \mathrm{C}$, as discussed above. The calculated interlayer spacing values confirm that carbon is graphitized to a higher degree at pre-pyrolysis 

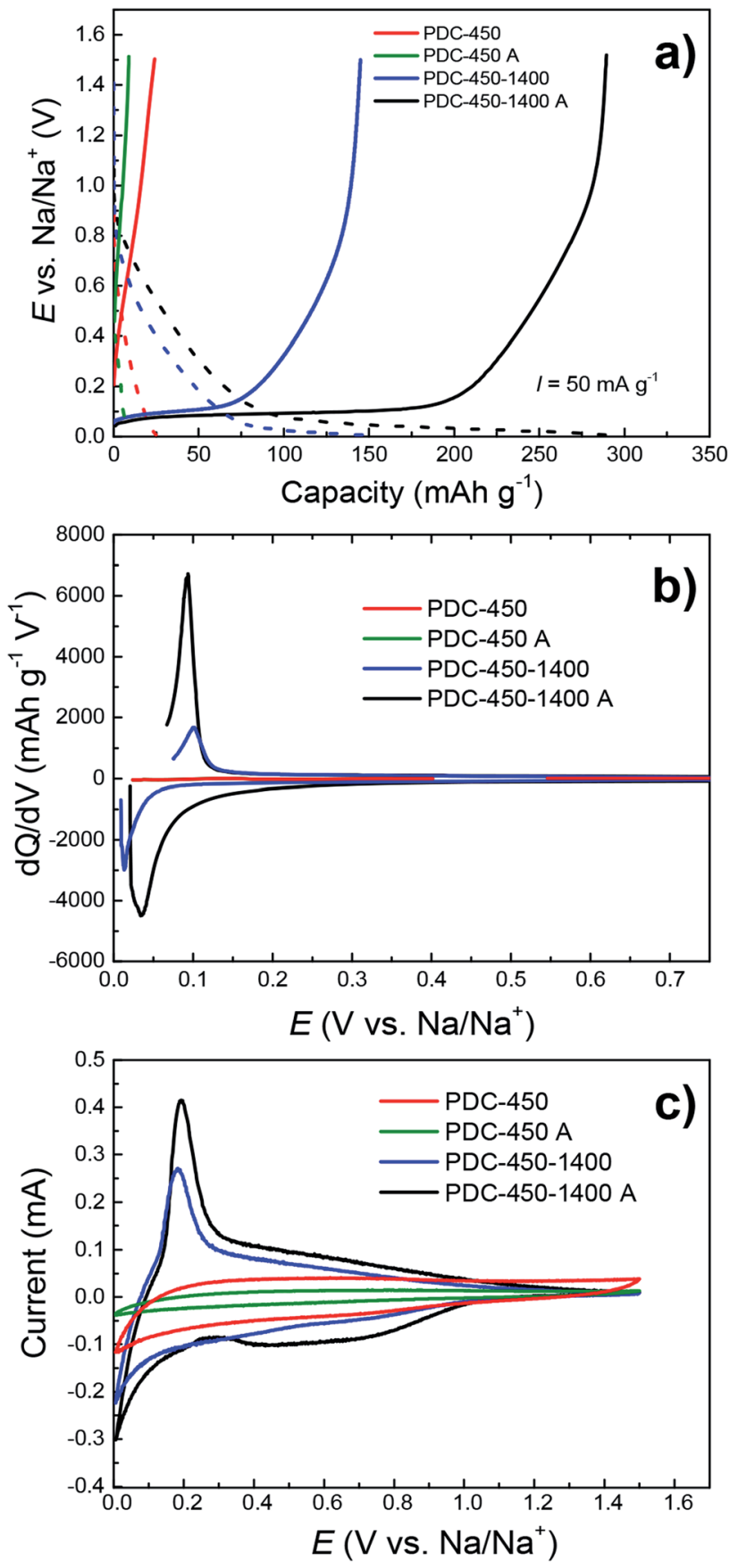

Fig. $6 \mathrm{CC}$ charge/discharge (a), dQ/dV (b) and CV (c) curves with the potential sweep rate of $0.1 \mathrm{mV} \mathrm{s}{ }^{-1}$, demonstrating the effect of synthesis steps ( $\mathrm{A}$ appended if $\mathrm{KOH}-\mathrm{HCl}$ treatment was used) on capacity in $\mathrm{NaPF}_{6} \mathrm{EC}: \mathrm{PC}(1: 1)$ electrolyte.

temperatures in the range of $600-800{ }^{\circ} \mathrm{C}$. However, the interlayer spacing values calculated for PDC-(300-500)-1400 A are characteristic for hard carbons, which agrees well with Raman spectroscopy and gas sorption measurement results.

\section{Raman spectroscopy}

The correlation between both graphitization (rise of $\mathrm{sp}^{3}$ carbon content) and non-carbon compound content is also supported by the shape of Raman spectra. The materials synthesized at $T_{1}$ $=600{ }^{\circ} \mathrm{C}$ and $T_{1}=800{ }^{\circ} \mathrm{C}$ and post-pyrolysed at $T_{2}=1400{ }^{\circ} \mathrm{C}$ demonstrate a distinctive $2 \mathrm{D}$ peak, indicating the existence of graphene layers and turbostratic carbon structure on the surface. ${ }^{41}$ The carbon materials with more distinct second-order region in their Raman spectra $\left(T_{1}>600{ }^{\circ} \mathrm{C}\right)$ also demonstrate $d_{002}$ reflexes with higher intensity in the XRD measurements, indicating a higher degree of graphitization (Fig. 4b).

Compared to the full width at half maximum values of the Dpeaks $\left(\mathrm{FWHM}_{\mathrm{D}}\right)$, the G-peaks $\left(\mathrm{FWHM}_{\mathrm{G}}\right)$ remain more or less the same with the rise of post-pyrolysis temperature. This indicates that the burn-off takes place at the expense of amorphous rather than graphitic carbon, which contributes to graphitization at higher pyrolysis temperatures. This is further supported by Fig. 4c and $\mathrm{d}$, which demonstrate that the $I_{\mathrm{D}} / I_{\mathrm{G}}$ ratio increases and FWHM $_{\mathrm{G}}$ decreases with the post-pyrolysis temperature, indicating somewhat higher disordering in the carbon structure, similar phenomena and tendencies have been reported in literature. ${ }^{\mathbf{4 2 , 4 3}}$

\section{Gas sorption results}

Specific surface area, calculated from gas $\left(\mathrm{N}_{2}, \mathrm{Ar}\right)$ sorption data, increases with pre-pyrolysis temperature $S_{\mathrm{BET}}=6 \mathrm{~m}^{2} \mathrm{~g}^{-1}$ for PDC-450-1400 A, while $S_{\text {BET }}=222 \mathrm{~m}^{2} \mathrm{~g}^{-1}$ for PDC-800-1400 A (Fig. 5). Compared to the pre-pyrolysis temperature, the postpyrolysis temperature has a minor effect on the specific surface area. Post-pyrolysis lowers the surface area in general (Table $\mathrm{S} 1 \dagger$ ), but pre-pyrolysis temperature sets the range (Fig. 5), in terms of structural modifiability. The structure of carbon synthesized at lower pre-pyrolysis temperatures $\left(T_{1}<600{ }^{\circ} \mathrm{C}\right)$ is rather amorphous and therefore more modifiable. Therefore, lower pre-pyrolysis temperature allows for more burn-off at the later post-pyrolysis stage, which, in turn, allows for materials with lower surface areas.

The values of specific surface area calculated from Ar and $\mathrm{N}_{2}$ sorption data are comparable, indicating that the surface of synthesized carbons is free of functional groups, which would interact with $\mathrm{N}_{2}$.

\section{Electrochemical characterization}

It has been proposed in several studies ${ }^{\mathbf{4 2 , 4 4}}$ that the mechanism for storing sodium ions in hard carbon is a two-step process. It is believed that sodium ions first adsorb on the hard carbon surface at $0.2 \mathrm{~V}<E<1.0 \mathrm{~V} v s . \mathrm{Na} / \mathrm{Na}^{+}$. Thereafter, the insertion of sodium ions into micropores that exist in the interlayer of local graphitic domains takes place (at $0 \mathrm{~V}<E<0.2 \mathrm{~V} v s$. Na/Na ${ }^{+}$). Therefore, the obtained hard carbon should have graphitic microcrystallites, but should not be fully graphitized. In this paper, our aim was to synthesize some hard carbon materials that would have the optimal graphitization degree i.e. a optimized surface area, specific interlayer distance, $I_{\mathrm{D}} / I_{\mathrm{G}}$ value and other properties characteristic of a hard carbon anode material.

Cycling performance and constant current (CC) discharge data (Fig. 7a-e) show very high capacity of $328 \mathrm{~mA} \mathrm{~h} \mathrm{~g}^{-1}$ with a plateau region $\left(E<0.2 \mathrm{~V} v s . \mathrm{Na} / \mathrm{Na}^{+}\right)$capacity of $243 \mathrm{~mA} \mathrm{~h} \mathrm{~g}^{-1}$ for PDC-450-1400 A at the current density of $50 \mathrm{~mA} \mathrm{~g}^{-1}$ (0.14C). At charging current of $25 \mathrm{~mA} \mathrm{~g}^{-1}$ (0.07C), even higher 

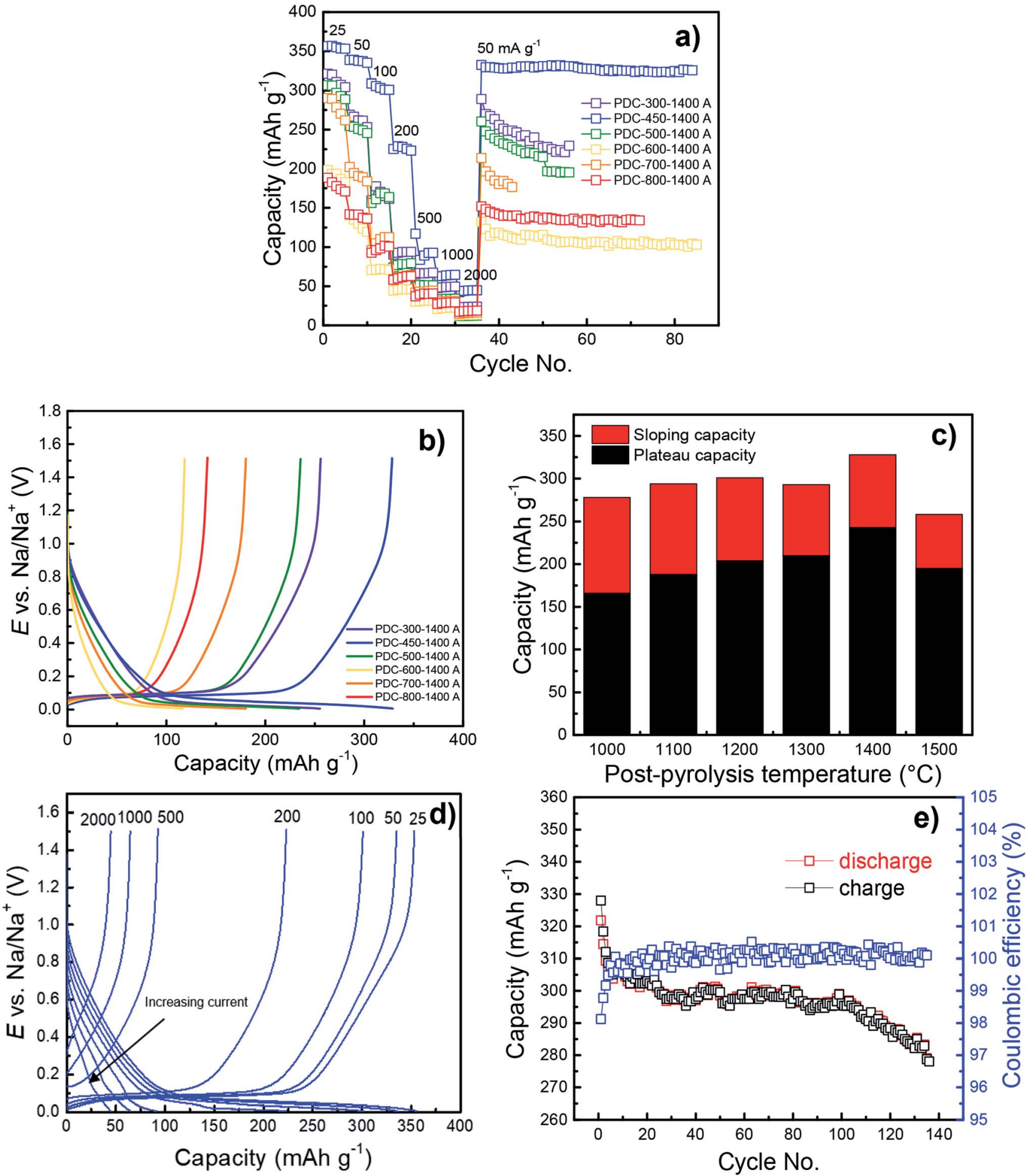

Fig. 7 Cycling performance (a) and CC charge/discharge curves at $50 \mathrm{~mA} \mathrm{~g}^{-1}$ (b) for PDC- $T_{1}-1400$ A. Plateau and sloping capacities for PDC$450-T_{2} A$ at $50 \mathrm{~mA} \mathrm{~g}^{-1}$ (c), CC charge/discharge curves for PDC-450-1400 A at different current densities (25-2000 mA g ${ }^{-1}$ ) (d) and a lifetime measurement for PDC-450-1400 A at $25 \mathrm{~mA} \mathrm{~g}^{-1}$ (e).

capacities were reached $-350 \mathrm{~mA} \mathrm{~h} \mathrm{~g}{ }^{-1}$ with a plateau region capacity of $250 \mathrm{~mA} \mathrm{~h} \mathrm{~g}^{-1}$. The C-rates have been calculated for $350 \mathrm{~mA} \mathrm{~h} \mathrm{~g}^{-1}$ theoretical capacity $\left(1 \mathrm{C}=350 \mathrm{~mA} \mathrm{~g}^{-1}\right)$. A longterm measurement demonstrates relatively high stability of PDC-450-1400 A. After about 130 charge/discharge cycles, the capacity stabilized at $280 \mathrm{~mA} \mathrm{~h} \mathrm{~g}^{-1}$, with the initial capacity of $320 \mathrm{~mA} \mathrm{~h} \mathrm{~g}^{-1}$ (Fig. 7e). PDC-450-1400 A exhibited a somewhat high ICE of $80 \%$ (Table 1 and Fig. S3 $\dagger$ ). The highest capacities were achieved with hard carbon materials that had low specific surface areas, broad 002 peak in XRD diffractograms, 
interlayer spacing of about $3.9 \AA$ and optimal $I_{\mathrm{D}} / I_{\mathrm{G}}$ values around 1.50 (PDC-450-1400 A for example). This might indicate the existence of microcrystallites and provide an explanation for the high capacities.

\section{Effect of synthesis steps on capacity}

The need for all three synthesis steps (pre-pyrolysis, $\mathrm{KOH}$ and $\mathrm{HCl}$ treatment, post-pyrolysis) is demonstrated in Fig. 6.

PDC-450-1400 A-the hard carbon treated with all 3 synthesis steps has the highest capacity, while the materials synthesized with fewer steps have significantly lower capacities. The lower capacities of PDC-450 and PDC-450-1400 can be explained by differences in their elemental composition, since these hard carbons have very high impurity content (Table $\mathrm{S} 2 \dagger$ ), which cause the graphitization of pre-pyrolysed materials. As mentioned before, it has been demonstrated in previous research papers ${ }^{\mathbf{4 0 , 4 5}}$ that elements like Fe and Ca can act as catalysts for the graphitization of carbon structure. Therefore we suggest, that the lower capacities of PDC-450 and PDC-450-1400 are caused by higher degree of graphitization, which in turn, is caused by differences in materials' elemental composition.

Surprisingly, when comparing PDC-450 and PDC-450 A, the latter has a somewhat lower capacity of the two. Since both carbons demonstrated very low capacities, the difference was also small, only $16 \mathrm{~mA} \mathrm{~h} \mathrm{~g}^{-1}$ with no identifiable plateau region. This is due to $\mathrm{KOH}$ and $\mathrm{HCl}$ treatment steps, during which the material might have become porous to an extent that is disruptive for sodium storage. A similar phenomenon was noted by Dou et al., ${ }^{30}$ where the carbonaceous material was activated with phosphoric acid.

\section{Effect of pre-pyrolysis temperature on capacity}

The pre-pyrolysis temperature is one of the key factors, which influences the performance of the peat-derived hard carbon in the half-cell charge-discharge measurements. Fig. 7a-e demonstrate that regardless of post-pyrolysis temperature, lower pre-pyrolysis temperatures allow for higher capacities, increasing from $141 \mathrm{~mA} \mathrm{~h} \mathrm{~g}^{-1}$ to $328 \mathrm{~mA} \mathrm{~h} \mathrm{~g}^{-1}$, the capacities of PDC-800-1400 A and PDC-450-1400 A, respectively. In part, this is due to lower specific surface areas of the materials prepared at lower $T_{1}$ (Fig. 5), causing higher ICE values (Fig. S3 $\dagger$ ), which in turn causes higher capacities. Also, hard carbons with higher pre-pyrolysis temperatures $\left(T_{1}>500{ }^{\circ} \mathrm{C}\right)$ have higher impurity content, which lowers their electrochemical capacities.

Although PDC-300-1400 A also has a relatively high capacity, its capacity does not surpass that of PDC-450-1400 A (Fig. 7b). Regarding the TGA data, PDC-300 has still a lot of mass to be burned off at higher temperatures. This implies that at $300{ }^{\circ} \mathrm{C}$, there may be different organic compounds in the material or structural properties that lower the capacity.

For a hard carbon to store sodium, it needs to have small graphitic domains ${ }^{\mathbf{1 9}}$ and when pyrolyzing peat at $300{ }^{\circ} \mathrm{C}$, it might be too amorphous to allow for effective sodium intercalation (Fig. 4a). The CC measurements data for PDC-600-1400 A also demonstrate much lower capacity that could be expected from the otherwise stable trend (the higher the pre-pyrolysis temperature, the lower capacity). Reasons for this can be found from the carbon characterization results.

As discussed earlier, the hard carbons obtained at $600{ }^{\circ} \mathrm{C}$ have significantly higher impurity content, higher surface area, smaller particles and a higher degree of graphitization. This suggests the formation of smaller particles in the pre-pyrolysis step that are more thoroughly graphitized, have less amorphous fraction and are therefore less efficient in sodium storage. In conclusion, lower pre-pyrolysis temperatures lead to materials with higher capacity, but the trend is not definite and may depend on the biomass precursor used.

\section{Effect of post-pyrolysis temperature on capacity}

The post-pyrolysis temperature has little effect on the capacity compared to pre-pyrolysis temperature. As a general trend, higher post-pyrolysis temperature leads to higher capacity (Fig. S4 $\dagger$ ), but the biggest impact the higher post-pyrolysis temperature has, is on the plateau capacity (Fig. 7c). Plateau capacities increase significantly (from 166 to $245 \mathrm{~mA} \mathrm{~h} \mathrm{~g}^{-1}$ ) with the increase of post-pyrolysis temperature, which is probably caused by slight structural disordering in the carbon structure.

However, Fig. 7b and c demonstrate that PDC-450-1500 A deviates from this trend, as both the sloping and plateau capacity decrease significantly (257 $\mathrm{mA} \mathrm{h} \mathrm{g}^{-1}$ and $194 \mathrm{~mA} \mathrm{~h} \mathrm{~g}^{-1}$, respectively). A similar effect has been noted in the literature. ${ }^{29}$

The increase of the plateau capacity is probably caused by burn-off of amorphous carbon, which makes the local graphitic domains more attainable and prominent and therefore allows for better sodium storage capability. Post-pyrolysing of the carbonaceous materials also lowers the surface area, which also leads to higher ICE values (Table 1).

\section{The influence of electrolyte}

The measurements of the materials prepared in this work were carried out in $1 \mathrm{M} \mathrm{NaPF}_{6} \mathrm{EC}: \mathrm{PC}(1: 1)$ as well as $1 \mathrm{M} \mathrm{NaClO}_{4}$ EC : DEC $(1: 1)$ electrolytes in order to compare two of the most common electrolyte solutions and their effect on the electrochemical behaviour of the carbons obtained. Fig. $\mathrm{S} 4 \dagger$ demonstrates that better results have been established for the $1 \mathrm{M} \mathrm{NaClO}_{4}$ EC : DEC $(1: 1)$ based system. Both the capacity at $1.5 \mathrm{~V}$ and plateau capacity are remarkably higher in the case of PDC-450-(1000-1500) A based half-cells, where the plateau capacity increases from 218 to $245 \mathrm{~mA} \mathrm{~h} \mathrm{~g}^{-1}$. This might be partly due to the significantly lower dielectric constant of the EC : DEC mixture. EC has a dielectric constant of 89.78, whereas for DEC it's 2.81 (ref. 46) and therefore the migration of sodium ions might have been enhanced. The potential cointercalation of $\mathrm{PC}^{47}$ and the possible impurities in $\mathrm{NaPF}_{6}$ might also have been the reasons for this discrepancy in the measurements.

\section{Conclusions}

A complex synthesis method has been developed for the preparation of the hard carbon materials from highly decomposed 
Estonian peat. Hard carbons were obtained by pre-pyrolysing, followed by treating with base and acid solutions and finally by post-pyrolysing the material. We have synthesized some hard carbon materials that demonstrated high capacities in sodiumion battery half-cells and according to physical characterizations data, the optimal graphitization degree and level of purity has been achieved to allow for effective sodium storage. The combination of lowering the pre-pyrolysis temperature and increasing the post-pyrolysis temperature has an enormous effect on the structural properties of the hard carbons while maintaining some of the peat's cellular structure. Using the multiple synthesis steps enables to change the ordering of the carbon structure and impact the surface area - carbon materials with surface areas as low as $6 \mathrm{~m}^{2} \mathrm{~g}^{-1}$ were prepared. Peat contains many impurities (mostly Ca and Fe hydroxides), which lower the capacity significantly. However, the $\mathrm{KOH}$ and $\mathrm{HCl}$ treatment steps are extremely effective in removing these impurities from materials that have been previously pyrolyzed at lower temperatures $\left(300-500{ }^{\circ} \mathrm{C}\right)$, enhancing noticeably the half-cell capacity. However, the removal of impurities is not effective in the case of the materials pre-pyrolysed at higher temperatures $\left(600-800{ }^{\circ} \mathrm{C}\right)$. These materials become too graphitic in the post-pyrolysis stage and therefore have very low capacities (of $\sim 130 \mathrm{~mA} \mathrm{~h} \mathrm{~g}{ }^{-1}$ ). However, the $\mathrm{KOH}$ and $\mathrm{HCl}$ treatment steps of the hard carbons pre-pyrolysed at $450{ }^{\circ} \mathrm{C}$, elevate the capacity from 141 to $328 \mathrm{~mA} \mathrm{~h} \mathrm{~g}^{-1}$. The best results have been obtained for PDC-450-1400 A - the peat material prepyrolysed at $450{ }^{\circ} \mathrm{C}$, treated with $\mathrm{KOH}$ and $\mathrm{HCl}$ and postpyrolysed at $1400{ }^{\circ} \mathrm{C}$. PDC-450-1400 A demonstrated great sodium storage capability, achieving a reversible capacity of $330 \mathrm{~mA} \mathrm{~h} \mathrm{~g}^{-1}$ with a plateau region of $245 \mathrm{~mA} \mathrm{~h} \mathrm{~g}^{-1}$ at $50 \mathrm{~mA} \mathrm{~g}^{-1}$ current density ( $350 \mathrm{~mA} \mathrm{~h} \mathrm{~g}^{-1}$ with a plateau of $250 \mathrm{~mA} \mathrm{~h} \mathrm{~g}^{-1}$ at $25 \mathrm{~mA} \mathrm{~g}^{-1}$ ) and an $80 \%$ initial coulombic efficiency.

Based on the analysis of the electrochemical results the halfcells completed it has been established that peat can successfully be used as a precursor for obtaining the high capacity hard carbon electrode materials for the sodium-ion batteries.

\section{Author contributions}

A. Adamson and R.Väli conceived the idea. A. Adamson and M. Paalo synthesised the hard carbon materials. A. Adamson performed the electrochemical measurements and analysed the data. J. Aruväli performed the XRF and XRD measurements and analysed the data. M. Koppel and R. Palm conducted the gas sorption measurements and analysed the data. E. Härk performed the TEM measurements. J. Nerut performed the TGA measurements and analysed the data. T. Romann performed the Raman measurements and A. Adamson analysed the data. E. Lust and A. Jänes provided the funding for the research paper and contributed to the idea. A. Adamson wrote the manuscript. R. Väli, E. Lust and A. Jänes edited the manuscript and supervised. All authors have given approval to the final version of the manuscript.

\section{Conflicts of interest}

There are no conflicts to declare.

\section{Acknowledgements}

This work was supported by "Activated carbon from peat" project LLTOM17351, by the EU through the European Regional Development Fund under projects TK141 "Advanced materials and high-technology devices for energy recuperation systems" (2014-2020.4.01.15-0011), Institutional Research under Grant IUT20-13 and Personal Research Grant PRG 676. The authors would also like to thank Mrs Riinu Härmas and Dr Karmen Lust for reviewing the manuscript, Ms. Eva-Liisa Tooming for carbon synthesis and Dr Rutha Jäger for SEM measurements.

\section{Notes and references}

1 J. Rockström, W. Steffen, K. Noone, Å. Persson, F. S. Chapin, E. F. Lambin, T. M. Lenton, M. Scheffer, C. Folke, H. J. Schellnhuber, B. Nykvist, C. A. de Wit, T. Hughes, S. van der Leeuw, H. Rodhe, S. Sörlin, P. K. Snyder, R. Costanza, U. Svedin, M. Falkenmark, L. Karlberg, R. W. Corell, V. J. Fabry, J. Hansen, B. Walker, D. Liverman, K. Richardson, P. Crutzen and J. A. Foley, Nature, 2009, 461, 472-475.

2 Z. Yang, J. Zhang, M. C. W. Kintner-Meyer, X. Lu, D. Choi, J. P. Lemmon and J. Liu, Chem. Rev., 2011, 111, 3577-3613.

3 M. Vetter and L. Rohr, in Lithium-Ion Batteries, Elsevier, 2014, pp. 293-309.

4 M. Li, J. Lu, Z. Chen and K. Amine, Adv. Mater., 2018, 30, 1800561.

5 C. Pillot, Lithium ion battery raw material Supply \& demand 2016-2025, PowerPoint presentation, Avicenne Energy, 2017.

6 M. Dahbi, N. Yabuuchi, K. Kubota, K. Tokiwa and S. Komaba, Phys. Chem. Chem. Phys., 2014, 16, 15007.

7 H. Pan, Y.-S. Hu and L. Chen, Energy Environ. Sci., 2013, 6, 2338-2360.

8 B. Dunn, H. Kamath and J.-M. Tarascon, Science, 2011, 334, 928-935.

9 J.-Y. Hwang, S.-T. Myung and Y.-K. Sun, Chem. Soc. Rev., 2017, 46, 3529-3614.

10 C. Vaalma, D. Buchholz, M. Weil and S. Passerini, Nat. Rev. Mater., 2018, 3, 18013.

11 R. Fong, U. von Sacken and J. R. Dahn, J. Electrochem. Soc., 1990, 137, 2009-2013.

12 C. Mao, M. Wood, L. David, S. J. An, Y. Sheng, Z. Du, H. M. Meyer, R. E. Ruther and D. L. Wood, J. Electrochem. Soc., 2018, 165, A1837-A1845.

13 P. Ge and M. Fouletier, Solid State Ionics, 1988, 28, 11721175.

14 K. Nobuhara, H. Nakayama, M. Nose, S. Nakanishi and H. Iba, J. Power Sources, 2013, 243, 585-587.

15 L. Li, Y. Zheng, S. Zhang, J. Yang, Z. Shao and Z. Guo, Energy Environ. Sci., 2018, 11, 2310-2340.

16 I. El Moctar, Q. Ni, Y. Bai, F. Wu and C. Wu, Funct. Mater. Lett., 2018, 11, 1830003.

17 D. A. Stevens and J. R. Dahn, J. Electrochem. Soc., 2001, 148, A803-A811.

18 C. Bommier, W. Luo, W.-Y. Gao, A. Greaney, S. Ma and X. Ji, Carbon, 2014, 76, 165-174. 
19 W. Luo, C. Bommier, Z. Jian, X. Li, R. Carter, S. Vail, Y. Lu, J.-J. Lee and X. Ji, ACS Appl. Mater. Interfaces, 2015, 7, 2626-2631.

20 H. Kumar, E. Detsi, D. P. Abraham and V. B. Shenoy, Chem. Mater., 2016, 28, 8930-8941.

21 M. Wahid, D. Puthusseri, Y. Gawli, N. Sharma and S. Ogale, ChemSusChem, 2018, 11, 506-526.

22 R. Väli, A. Jänes, T. Thomberg and E. Lust, J. Electrochem. Soc., 2016, 163, A1619-A1626.

23 R. Väli, A. Jänes, T. Thomberg and E. Lust, Electrochim. Acta, 2017, 253, 536-544.

24 K. Hong, L. Qie, R. Zeng, Z. Yi, W. Zhang, D. Wang, W. Yin, C. Wu, Q. Fan, W. Zhang and Y. Huang, J. Mater. Chem. A, 2014, 2, 12733.

25 R. R. Gaddam, D. Yang, R. Narayan, K. Raju, N. A. Kumar and X. S. Zhao, Nano Energy, 2016, 26, 346-352.

26 N. Zhang, Q. Liu, W. Chen, M. Wan, X. Li, L. Wang, L. Xue and W. Zhang, J. Power Sources, 2018, 378, 331-337.

27 H. Li, F. Shen, W. Luo, J. Dai, X. Han, Y. Chen, Y. Yao, H. Zhu, K. Fu, E. Hitz and L. Hu, ACS Appl. Mater. Interfaces, 2016, 8, 2204-2210.

28 J. Ding, H. Wang, Z. Li, A. Kohandehghan, K. Cui, Z. Xu, B. Zahiri, X. Tan, E. M. Lotfabad, B. C. Olsen and D. Mitlin, ACS Nano, 2013, 7, 11004-11015.

29 T. Zhang, J. Mao, X. Liu, M. Xuan, K. Bi, X. L. Zhang, J. Hu, J. Fan, S. Chen and G. Shao, RSC Adv., 2017, 7, 41504-41511.

30 X. Dou, I. Hasa, D. Saurel, M. Jauregui, D. Buchholz, T. Rojo and S. Passerini, ChemSusChem, 2018, 11, 3276-3285.

31 M. Baquero, J. Anal. Appl. Pyrolysis, 2003, 70, 779-784.

32 E. M. Lotfabad, J. Ding, K. Cui, A. Kohandehghan, W. P. Kalisvaart, M. Hazelton and D. Mitlin, ACS Nano, 2014, 8, 7115-7129.
33 I. Izanzar, M. Dahbi, M. Kiso, S. Doubaji, S. Komaba and I. Saadoune, Carbon, 2018, 137, 165-173.

34 J. Jagiello and J. P. Olivier, Adsorption, 2013, 19, 777-783.

35 J. A. Persson, E. Johansson and C. Albano, Anal. Chem., 1986, 58, 1173-1178.

36 W. Zhao, H. Chen, N. Liu and J. Zhou, J. Therm. Anal. Calorim., 2014, 117, 489-497.

37 F. Girardello, R. Guégan, V. I. Esteves, I. J. R. Baumvol, M. M. D. Sierra, J. S. Crespo, A. N. Fernandes and M. Giovanela, Spectrosc. Lett., 2013, 46, 201-210.

38 G. A. Zickler, B. Smarsly, N. Gierlinger, H. Peterlik and O. Paris, Carbon, 2006, 44, 3239-3246.

39 A. Jänes, T. Thomberg, H. Kurig and E. Lust, Carbon, 2009, 47, 23-29.

40 E. Thompson, A. E. Danks, L. Bourgeois and Z. Schnepp, Green Chem., 2015, 17, 551-556.

41 A. C. Ferrari and D. M. Basko, Nat. Nano, 2013, 8, 235-246. 42 S. Qiu, L. Xiao, M. L. Sushko, K. S. Han, Y. Shao, M. Yan, X. Liang, L. Mai, J. Feng, Y. Cao, X. Ai, H. Yang and J. Liu, Adv. Energy Mater., 2017, 7, 1700403.

43 K. Wang, Y. Xu, Y. Li, V. Dravid, J. Wu and Y. Huang, J. Mater. Chem. A, 2019, 7, 3327-3335.

44 Y. Cao, L. Xiao, M. L. Sushko, W. Wang, B. Schwenzer, J. Xiao, Z. Nie, L. V. Saraf, Z. Yang and J. Liu, Nano Lett., 2012, 12, 3783-3787.

45 A. Ōya and S. Ōtani, Carbon, 1979, 17, 131-137.

46 A. Ponrouch, E. Marchante, M. Courty, J.-M. Tarascon and M. R. Palacín, Energy Environ. Sci., 2012, 5, 8572.

47 T. Abe, N. Kawabata, Y. Mizutani, M. Inaba and Z. Ogumi, J. Electrochem. Soc., 2003, 150, A257-A261. 